\title{
Co-spray-drying of a heme iron ingredient to decrease its pro-oxidant effect in lipid- containing foods
}

Mercedes Alemán ${ }^{a}$, Ricard Bou ${ }^{a, 1}$, Javier Polo ${ }^{b}$, Carmen Rodríguez $^{b}$, Alba Tres $^{a}$, Rafael Codony ${ }^{a}$ and Francesc Guardiola $^{a}$

${ }^{a}$ Nutrition and Food Science Department - XaRTA - INSA, Faculty of Pharmacy, University of Barcelona, Avinguda Joan XXIII s/n, E-08028 Barcelona, Spain

${ }^{b}$ R\&D Department, APC Europe S.A., Avinguda Sant Julià, Polígon Industrial El Congost, E-08403 Granollers, Spain

Permanent address: Institute of Food Science, Technology and Nutrition (ICTAN), Spanish National Research Council (CISC), C/José Antonio Novais 10, E-28040 Madrid, Spain

\section{Author emails:}

Mercedes Alemán: aleman.mercedes@gmail.com

Ricard Bou: ricard_bou@ictan.csic.es

Javier Polo: javier.polo@ampc-europe.com

Carmen Rodríguez: carmen.rodriguez@ampc-europe.com

Alba Tres: atres@ub.edu

Rafael Codony: rafaelcodony@ub.edu

Running title: Decreased pro-oxidant effect of heme iron co-spray-dried

\section{Corresponding author:}

Francesc Guardiola

Nutrition and Food Science Department - XaRTA - INSA, Faculty of Pharmacy, University of Barcelona, Avinguda Joan XXIII s/n, E-08028 Barcelona, Spain. Telephone: (+34) 93402 4508; fax (+34) 93403 5931; email: fguardiola@ub.edu. 


\section{Abstract}

Fortification of food products with non-heme or heme iron is a common strategy to overcome nutritional iron deficiency. Heme iron is highly bioavailable but it promotes oxidation, as do other iron forms. Palm oil is widely used in the formulation of bakery products and chocolate fillings. The work reported here aims to delay the onset of oxidation of a palm oil matrix fortified with heme iron, as a model for bakery products, through the use of ascorbyl palmitate $(0$ and $400 \mathrm{mg} / \mathrm{kg}$ ) and the co-spray-drying of the heme iron with calcium caseinate in two ratios (heme iron concentrate:caseinate, 2:1 and 1:1, w/w). Primary (peroxide value and lipid hydroperoxide content) and secondary ( $p$-anisidine value and hexanal content) oxidation were measured over one year of storage at room temperature in the dark. The combination of ascorbyl palmitate at $400 \mathrm{mg} / \mathrm{kg}$ and the co-spray-dried heme iron in a 1:1 ratio was the treatment that best protected iron fortified samples from oxidation during the storage time.

Keywords: Heme iron / Food fortification /Co-spray-drying/ Antioxidant / Oxidative stability

List of abbreviations used: AP, ascorbyl palmitate; AUC, area under the curve; $C A$, citric acid; CAS, calcium caseinate; CHP eq., cumene hydroperoxide equivalents; FAME, fatty acid methyl esters; FID, flame ionization detector; FOX, ferrous oxidation-xylenol orange; ICP-AES, inductively-coupled plasma atomic emission spectroscopy; LHP, lipid hydroperoxide; MAXLHP, maximum lipid hydroperoxide; MUFA, monounsaturated fatty acid; $p$-AnV, $p$-anisidine value; PUFA, polyunsaturated fatty acid; PV, peroxide value; RT, room temperature; SFA, saturated fatty acid; ST-MA, mixture of modified starch (sodium octenyl succinate):maltodextrin $(1: 1, \mathrm{w} / \mathrm{w})$; trans $\mathrm{FA}$, trans fatty acid; TMAX, time to reach the maximum lipid hydroperoxide value.

Practical applications: Food fortification with iron has been suggested as a good strategy for overcoming iron deficiency. In this study, a heme iron ingredient has been selected due to its higher bioavailability than inorganic iron forms. Nevertheless, as other iron forms, heme iron is a potent pro-oxidant, which may affect the nutritional value, the sensory properties and shelf life of the fortified product. Thus, in this study the cospray-drying of the heme iron with several coatings was assessed in order to reduce its pro-oxidant activity. The different heme irons were mixed with palm oil, which is a fat widely used in bakery. The combination of co-spray-dried heme iron and ascorbyl palmitate delayed the onset of oxidation, which demonstrates its effectiveness in future iron fortified bakery products. 


\section{Introduction}

Iron deficiency is one of the most prevalent health issues in the world. It mainly affects infants, children and women [1]. However, its prevalence in pre-school age children is higher than that of any other population group [2]. This nutritional deficiency occurs during childhood as a result of a sustained negative iron balance, which may be caused by inadequate dietary intake or absorption of iron and increased requirements during the growth period. In later stages of iron depletion, the haemoglobin concentration decreases possibly leading to anaemia, which is the most severe consequence as it has been linked to childhood morbidity, impaired cognitive development and inadequate school performance.

Three major intervention strategies are used to overcome iron deficiency: diet diversification, iron supplementation and food fortification. Food fortification is known to be the most cost-effective long-term strategy to reduce the prevalence of iron deficiency [3]. A successful fortification programme requires proper selecting of the target population, the iron form and the food vehicle [4]. It is essential that the food vehicle either forms part of the regular diet of the target population or is easy to introduce into it [4]. Biscuits fortified with heme iron have been shown to be effective at improving the iron status of school-age children $[5,6]$.

Both heme and inorganic forms of iron have been used in food fortification programmes $[7,8]$. The bioavailability of heme iron is higher than that of inorganic iron due to its different absorption process [9] and because it is not affected by food ligands commonly present in typical diets [10]. Despite its dark colour, which limits its use and product acceptability, heme iron has been used in different food matrixes [11]. Products containing chocolate, besides being well accepted by children, mask the dark colour of the heme iron ingredient. However, all iron forms are potent pro-oxidants which can affect the shelf life, sensory properties and nutritional value of the fortified product [12]. To ameliorate this problem several strategies, such as antioxidant addition, iron encapsulation or addition of chelating agents, have been employed in foods fortified with either heme or inorganic iron [13-15].

In order to reduce these drawbacks, in two previous studies $[16,17]$, we evaluated models for iron fortification in baked products consisting of refined palm oil fortified with a heme iron ingredient (AproFER $1000^{\mathrm{TM}}$ ) and antioxidants. In these studies, the models were heated at $220^{\circ} \mathrm{C}$ for $10 \mathrm{~min}$ to mimic typical conditions during baking processing. In the first of the two studies [16], the palm oil matrix was used to assess the effectiveness of three antioxidants, ascorbyl palmitate (AP), citric acid (CA) and tocopherol extract, at delaying the onset of oxidation during storage for 200 days at room temperature (RT) in the dark. The tocopherol extract and CA alone were ineffective; whereas AP alone proved to be highly effective in preventing oxidation of samples during the storage period. In addition, a slight synergistic effect was observed when AP and CA were combined [16]. Taking these results into account, in the second study [17], the same model was used to attempt to optimize the dose of AP and CA to prevent oxidation. Four different concentrations of AP were combined using a factorial design with three different concentrations of CA. Primary and secondary oxidation parameters were monitored in samples over a 360-day storage period at RT in the dark. AP ( $400 \mathrm{mg} / \mathrm{kg}$ ) proved to be highly effective in delaying oxidation during storage; however, in that study CA acted as a pro-oxidant and no synergistic effect between the two antioxidants was observed [17].

Despite the fact that the pro-oxidant effect of iron in foods is well known, the oxidative stability of iron fortified food products has scarcely been studied [18-21]. In addition, to our knowledge, only Bovell-Benjamin et al. [15] studied how antioxidant addition affects lipid oxidation in iron fortified foods. These authors observed that the addition of butylated hydroxyanisole in maize meal porridges fortified with non-heme iron prevented hexanal formation and improved sensory acceptance during storage $[15,20]$. Another approach to prevent oxidation consist in the encapsulation of iron forms in order to decrease their reactivity [22]. The addition of non-heme iron forms encapsulated with different coating materials has been studied by different authors in several foods [23, 24] and in some cases a reduction of lipid oxidation, in comparison with the nonencapsulated iron forms, has been observed [25-29]. However, to our knowledge, there are no studies in the literature dealing with the use of encapsulated heme iron in food fortification.

Therefore, one aim of the present work was to assess how the co-spray-drying of heme iron with different coating materials (calcium caseinate or a mixture of modified starch and maltodextrin) reduces the pro- 
oxidant effect of heme iron. In order to rapidly select the most effective coating material, a preliminary study was conducted using a model that consisted of sunflower oil stored at $60^{\circ} \mathrm{C}$. This study showed that the cospray-drying of heme iron with calcium caseinate was more effective to prevent lipid oxidation. Subsequently, it was studied how the heme iron co-spray-dried with calcium caseinate, alone or in combination with the addition of AP (at $400 \mathrm{mg} / \mathrm{kg}$ ), affects the lipid oxidation in a palm oil model stored at RT in the dark for 360 days.

\section{Materials and methods}

\subsection{Materials}

Refined palm oil was a gift from Lípidos Santiga S.A. (Santa Perpètua de Mogoda, Spain). Sunflower oil was purchased in a local market. AP (99.5\%) and hexanal (98\%) were acquired from Sigma-Aldrich (Madrid, Spain). Calcium caseinate (CAS), and a mixture of modified starch (sodium octenyl succinate) and maltodextrin (1:1, w/w) (ST-MA) were purchased from Cargill S.L.U. (Rubí, Spain). Dimethyl sulphoxide (headspace grade) was acquired from Scharlab S.L. (Barcelona, Spain).

All the chemicals used were of ACS grade with the exception of the solvents used in the ferrous oxidationxylenol orange (FOX) method, in the tocopherol and tocotrienol determination and in the heme iron determination, which were of HPLC grade. The iron standard solution was purchased from High-Purity Standards (Charleston, SC) and was traceable to the Standard Reference Materials of NIST.

\subsection{Producing heme iron ingredients}

Heme iron ingredients were produced at APC Europe S.A. (Granollers, Spain). The heme iron ingredient used as a control (AproFER $1000^{\mathrm{TM}}$ ) is a dark powder obtained from the blood of healthy pigs as described by González Rosendo et al.[30]. Briefly, after separating the blood cell fraction by centrifugation, a pressure pump was used to release the haemoglobin contained in the red blood cells. The haemoglobin was then enzymatically hydrolyzed using a proteolytic enzyme (Alcalase ${ }^{\circledR}$, Novo-Nordisk, Denmark) in controlled pH and temperature conditions. Following, the heme group was concentrated by ultrafiltration and spray-dried. The resulting control heme iron ingredient is a proteinaceous material (mix of peptones, peptides and free amino acids) that contains around $1 \%$ of total iron.

For the preliminary study, five different ingredients were manufactured: the heme iron control and four cospray-dried ingredients, two with CAS and two with ST-MA at two ratios (2:1 and 1:1, w/w, heme iron concentrate:co-spray-drying agent). For the main study, three different ingredients were prepared: the heme iron control and two co-spray-dried ingredients with CAS at the ratios 2:1 and 1:1, w/w, heme iron concentrate:CAS. More detailed information on heme iron ingredient manufacture is given as supplementary information.

\subsection{Study design and sample preparation}

Two studies were planned and sequentially conducted. The preliminary study aimed to select the most effective co-spray-drying agent (CAS or ST-MD) to reduce the pro-oxidant effect of heme iron. To do this selection, we used a model that consisted of sunflower oil stored at $60^{\circ} \mathrm{C}$. Sunflower oil was used in this accelerated storage study due to it is more susceptible to oxidation than palm oil. Subsequently, in the main study it was assessed how the heme iron co-spray-dried with the most effective agent (CAS), alone or in combination with the addition of AP (at $400 \mathrm{mg} / \mathrm{kg}$ ), affects the lipid oxidation in a palm oil model stored at RT in the dark for 360 days.

\subsubsection{Preliminary study (accelerated storage conditions)}

Mixtures of sunflower oil fortified with heme iron were prepared at $40^{\circ} \mathrm{C}$ under magnetic stirring. The 5 heme iron ingredients were dispersed in the sunflower oil matrix in different percentages $\left(8.7 \%\right.$ control AproFER ${ }^{\mathrm{TM}}$, 16.0\% ST-MD and CAS at 1:1 ratio and 12.5\% ST-MD and CAS at ratio 2:1; all expressed in w/w basis) in order 
to maintain the iron content of all the samples constant (1.30 mg Fe/g mixture). The iron content was higher in this study than in the main study with palm oil because we aimed to ensure the selection of the best co-spraydrying agent to protect against lipid oxidation.

Once the heme iron ingredients were homogenously dispersed in the sunflower oil, the mixtures were heated at $220^{\circ} \mathrm{C}$ for $10 \mathrm{~min}$ to mimic the typical baking conditions. Thereafter, the mixtures were stored at $60^{\circ} \mathrm{C}$ in an oven. Sampling was conducted as follows: at specific times, the sunflower oil mixtures were removed from the oven and homogenized by magnetic stirring for $5 \mathrm{~min}$ and, immediately after, vials were filled with sample aliquots, flushed with nitrogen, capped and stored at $-20^{\circ} \mathrm{C}$ till analysis.

The evolution of the oxidation of the samples was followed by means of the peroxide value (PV) [31] and $p$ anisidine value ( $p$-AnV) [32]. Before performing the assays, the samples were thawed at RT and filtered through Whatman paper no. 54 under vacuum to remove heme iron particles. The oxidation was followed till the control sample reached a PV higher than $100 \mathrm{mEq} \mathrm{O} / \mathrm{kg}$. Both the heme and total iron content of the samples were assessed without removing heme iron particles.

\subsubsection{Main study (storage at room temperature).}

Refined palm oil was chosen because it is commonly used to manufacture biscuits, pastries and chocolate fillings, amongst others. Three different heme iron ingredients were evaluated: the control AproFER $1000^{\mathrm{TM}}$ and two ingredients obtained by co-spray-drying of heme iron with CAS in two ratios (2:1 and 1:1, w/w). Both ingredients co-spray-dried with CAS were selected because they showed a high capacity to retard the onset of oxidation in the preliminary experiment.

As the different heme iron ingredients contained different amounts of iron, different quantities of the heme iron ingredients were dispersed into the palm oil in order to maintain constant the iron content of all samples (1.20 mg Fe/g sample). Theoretically, by using these heme iron dispersions in palm oil to prepare the chocolate fillings for chocolate-filled biscuits, 2 biscuits would provide approximately $32 \%$ of the iron RDA (14 $\mathrm{mg} \mathrm{Fe} /$ day [33]). To that aim, a sandwich - type cookie weighting $25 \mathrm{~g}$ and having $7.5 \mathrm{~g}$ of chocolate filling with a $25 \%$ palm oil has been considered.

The three heme iron ingredients were combined with two concentrations of AP ( 0 and $400 \mathrm{mg} / \mathrm{kg}$ ). AP was added at $400 \mathrm{mg} / \mathrm{kg}$ because this concentration was found to delay the onset of oxidation in similar palm oil models fortified with heme iron [16, 17]. We included an additional treatment in which the control heme iron ingredient (AproFER 1000 ${ }^{\mathrm{TM}}$ ) and CAS were mixed (without being co-spray-dried) at 1:1 $(\mathrm{w} / \mathrm{w})$ ratio. With this latter treatment, we aimed to assess the antioxidant properties of CAS by itself (Table 1 ).

Samples were prepared as described elsewhere [17] with few modifications. The palm oil was melted $\left(55^{\circ} \mathrm{C}\right)$, mixed and divided into seven aliquots. The aliquots were heated at $140^{\circ} \mathrm{C}$ and AP or CAS was dispersed under stirring. Thereafter, the heme iron ingredients were dispersed in the same manner. The samples were then heated at $220^{\circ} \mathrm{C}$ for $10 \mathrm{~min}$ to reproduce typical baking conditions. The samples were allowed to cool to $70^{\circ} \mathrm{C}$ $80^{\circ} \mathrm{C}$, homogenized using a Polytron PT3100 (10 sec, $15000 \mathrm{rpm}$ ) and distributed into 10 and $20 \mathrm{~mL}$ vials. The vials were completely filled up, closed, shaken and introduced into an ice bath until the content was solid to ensure an even dispersion of the heme iron ingredients. The vials were stored at RT in the dark for $0,90,180$ and 360 days, and then the samples were frozen at $-20^{\circ} \mathrm{C}$ until analysis. In various determinations (tocopherol content, PV, lipid hydroperoxide (LHP) content and $p-\mathrm{AnV}$ ), the vials were heated to $55^{\circ} \mathrm{C}$ for $15 \mathrm{~min}$ and then the samples were filtered under vacuum through Whatman no. 54 filter paper at RT to remove the heme iron particles. Heme iron, total iron and hexanal content were determined without removing the iron particles from the sample.

\subsection{Palm oil characterization}

The fatty acid (FA) composition, and tocopherol and tocotrienol content of the refined palm oil used to prepare the heme iron dispersions were determined. Fatty acid methyl esters (FAME) were prepared as described elsewhere [34] and were determined according to the chromatographic conditions described by 
Alemán et al. [16]. The tocopherol and tocotrienol content was determined in $200 \mathrm{mg}$ samples (of the palm oil used to prepare all the treatments and the palm oils obtained by filtration of the treatment samples after the thermal treatment) by normal-phase HPLC as described by Alemán et al [16]. Also, PV [31], LHP content (using the non-induced FOX method) [35], p-AnV [32] and hexanal content [17] were assessed in the fresh palm oil.

\subsection{Heme and total iron content}

The heme iron content of the different heme iron ingredients and also of the samples prior to storage was determined according to Hornsey [36]. The total iron content of the heme iron ingredients and samples was determined after their mineralization using a PerkinElmer ICP-AES (Optima 3200 RL model, Whaltam, Massachusetts). The mineralization processes were performed as described elsewhere [17], with few modifications for samples (see supplementary information). The percentage of free iron in the samples was estimated subtracting the \% of heme iron (relative to total iron) from 100.

\subsection{Susceptibility to lipid oxidation}

In the palm oil study, the induced version of the FOX method was used to assess the susceptibility to lipid oxidation of the fortified palm oil samples, filtered after the thermal treatment $[37,38]$. In this assay, the amount of LHP in each filtered sample was measured over an incubation period, using the reaction conditions reported elsewhere [35]. The incubation time was set at $168 \mathrm{~h}$ and absorbance was measured at different times, following the method described by Tres et al. [39]. To better describe the differences observed in the susceptibility to oxidation of the samples, the following parameters were calculated [39]: Initial LHP (the initial LHP value was measured after 30 min of incubation), MAXLHP (the maximum LHP value), TMAX (the time to achieve the MAXLHP), Final LHP (the final LHP value measured after $168 \mathrm{~h}$ of incubation) and AUC (the area under the curve of LHP formation).

\subsection{Determination of oxidation during storage}

In the preliminary study, primary oxidation was monitored by means of the PV (European Communities Commission, 1991) and secondary oxidation by means of $p$-AnV [32].

Formation of primary oxidation compounds in palm oil study was assessed by means of PV (European Communities Commission, 1991) and measuring the LHP content through the non-induced FOX method after 30 min of reaction in the dark at RT [35]. The formation of secondary oxidation compounds was assessed by means of $p$-AnV [32] and hexanal content determined by static headspace [17].

\subsection{Statistical analysis}

Pearson's correlation coefficients were used to study the relationships between PV and LHP content and between $p-A n V$ and hexanal content in the palm oil study. One-way ANOVA was used to determine the effect of the different treatments on (I) tocopherol and tocotrienol content after heating at $220^{\circ} \mathrm{C}$ for $10 \mathrm{~min}$; and (II) the parameters of the induced FOX method. In addition, MANOVA was used to determine significant effects produced by the different treatments and storage times on PV, LHP content, $p$-AnV and hexanal content. The effect of the different treatments on PV, LHP content, $p$-AnV and hexanal content at each storage time was assessed by one-way ANOVA.

When significant differences were found, the means were separated using Scheffe's test $(\alpha=0.05)$. In all cases, $P \leq 0.05$ was considered significant.

\section{Results and discussion}

\subsection{Preliminary study with sunflower oil fortified with heme iron stored at $60^{\circ} \mathrm{C}$}

The samples containing the heme iron ingredients co-spray-dried with CAS or ST-MA presented lower PV than the control sample (not co-spray-dried) over the storage time (Figure 1.A). Furthermore, all the heme iron 
ingredients co-spray-dried at a 1:1 ratio were more effective at delaying the onset of PV than their corresponding heme iron ingredients co-spray-dried at a 2:1 ratio. It is important to note that the greatest delay in the onset of primary oxidation was achieved in samples with the heme iron ingredient co-spray-dried with CAS.

Secondary oxidation, as measured by $p$-AnV (Figure 1.B), increased from the beginning of the storage time in all the treatments, with the control sample reaching the highest $p$-AnV at the end of the storage time (340 h). Moreover, samples with the heme iron co-spray-dried in a 1:1 ratio with CAS presented the lowest $p$-AnV throughout the storage period.

In conclusion, the heme iron co-spray-dried with CAS at a 1:1 ratio showed the greatest delay in the onset of primary and secondary oxidation in the sunflower oil matrix stored at $60^{\circ} \mathrm{C}$. Therefore, CAS was selected as the co-spray-drying agent for the subsequent study with palm oil fortified with heme iron.

\subsection{Palm oil fortified with heme iron as a model for iron fortification in bakery products}

\subsubsection{Palm oil characterization and tocopherols and tocotrienols content after the heat treatment}

The FA composition of the palm oil used to prepare the iron fortified samples (Table 2) was the typical of this kind of oil [40]: $49.83 \%$ SFA; $39.93 \%$ MUFA; $10.24 \%$ PUFA and $0.11 \%$ trans FA.

The composition in tocopherols and tocotrienols of the palm oil (Table 3) was characteristic of this oil type [40], a high concentration of tocotrienols particularly alpha- and gamma-tocotrienol, was found. The total content of tocopherol and tocotrienol in the palm oil used to prepare the fortified samples was $632.4 \mathrm{mg} / \mathrm{kg}$ (total tocopherols: $193.2 \mathrm{mg} / \mathrm{kg}$ and total tocotrienols: $439.2 \mathrm{mg} / \mathrm{kg}$ ).

The tocopherol and tocotrienol content of the different fortified palm oil samples after the heat treatment $\left(220^{\circ} \mathrm{C}\right.$ for $\left.10 \mathrm{~min}\right)$, prior to storage, is shown in Table 3. Those samples with added AP had the same amount of total tocopherols as the non-heated palm oil. However, samples without AP (control, 1:1 and CAS) presented lower total tocopherol content than the non-heated palm oil. Thus, AP prevents the loss of tocopherols during heating, especially in the case of $\alpha$-tocopherol, which is the most abundant. Similar results were found for the total tocotrienol content and total tocopherols plus tocotrienols, which indicate the protective effect of AP during heating. The protective effect of the AP against tocopherol and tocotrienol oxidation has been previously reported in some foods and lipid models [39-42]. However, the mechanism of AP to preserve and/or regenerate the tocopherols is not clear, and two hypotheses have been pointed out for explaining this behaviour [42, 43, 45]: (i) AP is more sensitive than $\alpha$-tocopherol to radical attack; and (ii) AP has the ability of regenerating $\alpha$-tocopherol by donating a hydrogen to the tocopheroxyl radicals formed during the oxidation. In addition, other antioxidant mechanisms ascribed to AP [46-48], such as the oxygen scavenging and metal chelating, could contribute to tocopherol preservation.

Regarding the oxidation status, fresh palm oil had PV and LHP content of $0.04 \pm<0.01 \mathrm{mEq} \mathrm{O}_{2} / \mathrm{kg}$ oil and $0.14 \pm<0.01 \mathrm{mmol}$ CHP Eq/ $\mathrm{kg}$ oil, respectively $(n=5)$; while hexanal was not detected and the $p$-AnV was $1.24 \pm 0.05(n=5)$.

\subsubsection{Heme iron and total iron content}

Table 4 shows the heme and total iron content of the ingredients and samples prior to storage in both the sunflower and palm oil studies. The average total iron content was close to the target in both studies (1.27 and $1.20 \mathrm{mg} \mathrm{Fe} / \mathrm{g}$ sample).

The main difference between the ingredients used in each study was the percentage of heme iron. In the preliminary study, heme iron was $92 \%$ of total iron in the ingredients, while in the palm oil study it was $83 \%$. This heme iron content is lower than in the previous studies where heme iron accounted for $96 \%$ of the total iron content $[16,17]$. 
Heme iron was the main form present in the samples in both studies. In the palm oil study, the heating of the samples $\left(10 \mathrm{~min}\right.$ at $\left.220^{\circ} \mathrm{C}\right)$ liberated iron from the heme moiety and the heme iron percentage was reduced from $83 \%$ to $73 \%$ (Table 4 ). This resulted in large amounts of free iron (27\%) in the samples, which differs from the preliminary study, where the maximum amount of free iron in the samples was $6 \%-10 \%$ (from the heme iron ingredients), since iron liberation during the heating of samples was negligible (Table 4). The previous studies also showed that iron liberation during heating was negligible with a free iron content in the fortified samples accounting for $2 \%-4 \%$ of the total iron content $[16,17]$. These differences between studies in free iron may affect lipid oxidation development. The differences in iron liberation and free iron content could be due to small changes in the production conditions of the heme iron ingredients (e.g., ultrafiltration times, temperatures and pressures), since the production of some of these batches was used by the heme iron producer to assay new processing conditions. The main difference between the batches used in the present work for the sunflower and palm oil studies was the ultrafiltration step, which was a $15 \%$ longer for the palm oil batch. As commented above, this change clearly affects the percentage of heme iron in the batch and the iron liberation during heating (Table 4), but probably will affect other composition parameters of the ingredient. In addition, it has been reported that the haemoglobin hydrolysis conditions (e.g., enzyme type and dose, $\mathrm{pH}$, temperature, reaction time) affect the composition of the hydrolysates and their prooxidant/antioxidant balance [47-49]. This is due to the fact that the hydrolysis degree marks the peptide composition of the hydrolysate and their antioxidant properties, but also could affect iron liberation from the heme moiety. However, as the hydrolysis conditions were kept constant between studies, this step will not be the main cause of the observed differences between heme iron batches.

\subsubsection{Susceptibility to lipid oxidation (Induced FOX-method)}

The susceptibility to lipid oxidation of the samples was assessed prior to storage. Table 5 presents the parameters calculated from the different curves of LHP formation. The initial LHP value (measured after 30 min of incubation) indicates the amount of LHP already present in the samples [39]. These values show that the addition of calcium caseinate in a ratio of 1:1 with the heme iron, co-spray-dried or not, favoured the formation of LHP during the heating. These two treatments also presented higher MAXLHP and AUC values together with a lower TMAX. The AUC has been described as a good marker of susceptibility to oxidation in different matrices [16, 27]; therefore these results point out that samples with CAS in a 1:1 ratio without AP are more prone to oxidation than the other samples.

It is important to note that the time taken to reach the maximum LHP concentration (TMAX) varied between the samples. Those treatments that combined AP with the co-spray-dried ingredients presented much higher TMAX (48-43.5 h), especially compared with CAS and CAS 1:1 treatments $(2.5 \mathrm{~h})$. This result coincides with those found in previous studies $[16,17]$, where the TMAX was higher for palm oil matrixes fortified with heme iron with AP added.

\subsubsection{Assessment of oxidation during storage}

The development of LHP over the storage period was monitored by means of the PV and the LHP content (non-induced FOX method). Likewise, the formation of secondary oxidation products was assessed by the $p$ AnV and the hexanal content of the samples (Table 6).

\subsubsection{Primary oxidation: PV and LHP content}

The LHP content and PV of the samples were highly correlated $(r=0.921 ; p<0.0001, n=140$, see Figure S1 in supplementary materials). Therefore, the effects of the factors studied were similar on both parameters.

As opposed to what was found in the preliminary study, the co-spray-drying of the heme iron with CAS (irrespective of the ratio) did not protect the samples against primary oxidation (Table 6). Moreover, in previous studies of palm oil fortified with heme iron, the addition of AP prevented samples from primary oxidation [16, 17]; however, in this study this protective effect of AP was not seen as there were no 
differences between the control and the AP treatment. This is probably due to the increased free iron in this study, $27 \%$ compared to $2 \%-4 \%$ in the previous ones $[16,17]$.

Both PV and LHP content clearly increased during the storage of the samples at RT in the dark (Table 6). At time 0 , both control and CAS samples presented higher PV than the rest of samples, whereas LHP content was higher in CAS and CAS 1:1 samples; which agrees with the results for susceptibility to oxidation. At the end of the storage period, there was no difference between the control and the AP treatment regarding primary oxidation.

The increase of PV during storage at room temperature of iron fortified biscuits has been reported in the literature $[18,19]$. Different amounts of chelated iron $(0-1152 \mathrm{mg}$ of NaFeEDTA per $\mathrm{kg}$ ) were added to the dough formula of Petit Beurre biscuits, including $11 \%$ sunflower oil [19]. These biscuits were baked at $250^{\circ} \mathrm{C}$ for $7 \mathrm{~min}$, and the fortified samples (10.73-17.95 mg Fe/100 g biscuit) had initial PV that ranged from 0.46 to $0.70 \mathrm{mEq} \mathrm{O} / 2 / \mathrm{kg}$ lipid, which slightly increased up to $1.46-1.67 \mathrm{mEq} \mathrm{O} / \mathrm{kg}$ lipid after 60 days of storage at 17$20^{\circ} \mathrm{C}$ in polytheylene bags. These initial values are higher than those found in the present study (Table 6), which can be attributed to a number of reasons such as the increased susceptibility towards oxidation of sunflower oil compared to palm oil. However, it is difficult to find fully comparable oxidation results in the literature on iron fortified foods, because there are many variables affecting the results such as the form of added iron, food composition, and processing and storage conditions. In this context, the addition of a bovine heme iron concentrate in fortified biscuits (19.6 mg Fe/100 g biscuit), containing 9.5\% hydrogenated lard and cooked at $270^{\circ} \mathrm{C}$ for $10 \mathrm{~min}$, resulted in low PV at the beginning of the storage [18]. However, after 30 days of storage at $17-20^{\circ} \mathrm{C}$ in three different packaging materials (polyethylene, polyethylene-polypropylene and polyethylene-aluminum foil) the $\mathrm{PV}$ markedly increased up to $10-15 \mathrm{mEq} \mathrm{O}_{2} / \mathrm{kg}$ lipid.

\subsubsection{Secondary oxidation: $p$-AnV and Hexanal content}

The $p$-AnV and hexanal content of the samples were correlated $(r=0.442 ; p<0.0001, n=140$, see Figure S1 in supplementary materials). Therefore, the effects of the factors studied were similar on both parameters. The correlation between these two parameters is due to the fact that $p$-AnV measures the aldehyde content of the palm oil matrix. However, it is well known that the products of reaction between unsaturated aldehydes (particularly 2,4-dienals and 2-alkenals) and $p$-anisidine absorb much more strongly at $350 \mathrm{~nm}$ than reaction products coming from saturated aldehydes (e.g. hexanal). Thus, the $p$-AnV depends not only on the amount of aldehydic compounds present in the sample but also on their structure [32]. Other authors have also reported a significant positive correlation between $p-A n V$ and hexanal in different samples $[52,53]$. The correlation coefficients reported by these authors are higher than in our case $(0.81$ during frying with partially hydrogenated soybean oil and 0.94 during storage of Brazil nuts at high temperature). This difference can be explained because the amount and structure of aldehydic compounds formed during lipid oxidation depends on the FA composition of the fat $[54,55]$. Palm oil used in our study (Table 2 ) is more saturated and has much less linoleic acid than the partially hydrogenated soybean oil $(16: 0,11.87 \% ; 18: 0,7.41 \% ; 18: 1,40.49 \% ; 18: 2$, $37.9 \% ; 18: 3,2.33 \%)$ and Brazil nuts (16:0, 15\%; 18:0, 10\%; 18:1n-9, 29\%; 18:2n-6, 45\%) used in the previously commented studies $[52,53]$, which supports our explanation.

Those treatments that combined AP and the co-spray-dried ingredients (at any ratio) presented lower $p$-AnV than the rest of the treatments, even showing synergism between AP and the co-spray-dried ingredients (Table 6). Similarly, the hexanal content was reduced when AP was combined with the co-spray-dried ingredient in a 1:1 proportion. Furthermore, the $p$-AnV increased with time till the end of the storage period, whereas the hexanal content of the samples increased till day 180. The decrease in concentration of hexanal observed at the end of the storage period might be due to the formation of adducts between hexanal and the peptides from the heme iron ingredient [56].

At the beginning of the storage period (Table 6), the $p$-AnV of samples with AP was lower than for the other treatments; this supports the idea that AP offers oxidative protection during heat treatment of samples at $220^{\circ} \mathrm{C}$ during $10 \mathrm{~min}$. Similar conclusions were drawn regarding the tocopherol and tocotrienol content (Table 3), where samples with AP presented similar values to those of the non-heated palm oil, confirming the 
antioxidant effect of AP during heating. These results agree with those found in previous studies were AP protected palm oil fortified with heme iron from oxidation during the heat treatment $[16,17]$.

After 360 days of storage, no differences in secondary oxidation were observed between the CAS 1:1 treatments and the control, which differs from the findings of the preliminary study. Nevertheless, the samples that combined CAS 1:1 and AP reached the lowest $p$-AnV and hexanal content after 360 days of storage.

Overall, in this study, AP showed a protective effect during the heat treatment. However, AP was not observed to be effective over the storage time; which is the opposite of what was found in previous studies $[16,17]$. This must be related to differences between the matrixes used in the different studies carried out in our laboratory with heme iron (Table 7).

The FA and tocopherol compositions of palm oils used in the different studies are reported in Table 7. Differences between the percentages of MUFA, PUFA, linoleic and linolenic acid were small and do not help explaining the different AP effect between the studies. Conversely, we found important differences in total tocopherol and tocotrienol content of the palm oils, with the palm oil used in this study having the highest content. This may cause differences in the susceptibility to oxidation of samples from different studies, but both the loss of tocopherols and tocotrienols, and the AUC values in this study are similar to those in study 1 (Table 7). Moreover, the oxidation parameters in these two studies were similar, which disagrees with the difference in tocopherol and tocotrienol content. However, there is an important difference between the present study and study 1 , which is the amount of free iron. In this study, free iron content was much higher (27\%) than in study $1(4 \%)$. Therefore, the relative importance of the oxidation pathways would have been different, rendering $A P$, an oxygen scavenger, almost ineffective when added alone in the present study. Also, the higher free iron content in this study may have masked the effect of the higher tocopherol and tocotrienol content on the oxidation of the samples.

Indeed, if we compare studies 1 and 2, where the free iron content is similar (4\% vs. $2 \%$ ), differences in both susceptibility to oxidation and oxidation status are observed (with samples from study 2 being more prone to oxidation); which may be explained by the lower tocopherol and tocotrienol content in study 2 (Table 7).

\section{Conclusions}

The co-spray-drying of the heme iron, with either CAS or ST-MD, delayed the onset of both primary and secondary oxidation in sunflower oil fortified with heme iron stored at $60^{\circ} \mathrm{C}$. The more effective co-spraydrying agent was CAS.

However, in the palm oil study, the co-spray-drying of the heme iron with CAS did not delay the onset of oxidation. Moreover, the use of AP alone did not prevent either primary or secondary oxidation during storage of palm oil fortified with heme iron ingredients. Both these findings contradict what was found in previous studies and may be due to the fact that the matrix in this palm oil study contained a much higher amount of free iron than in the previous studies with palm oil ( $27 \%$ vs. $2 \%-4 \%$ ) or sunflower oil ( $27 \%$ vs. $6 \%-10 \%)$.

Nonetheless, the combination of AP and co-spray-drying of the heme iron with calcium caseinate protected the palm oil samples from oxidation; which indicates synergism between AP and co-spray-dried heme ingredients. Moreover, the samples that combined CAS 1:1 and AP reached the lowest $p$-AnV and hexanal content after 360 days of storage.

\section{Acknowledgement}

The authors thank Jordi Soler of Lípidos Santiga, S.A. (Santa Perpètua de Mogoda, Spain) for providing the refined palm oil; Jesus Ródenas of APC Europe, S.A. (Granollers, Spain) for his skilful help in the production of the co-spray-dried products; and Maite Romero and Francisco Menendez for their technical assistance in the total iron determination. 
This study received financial support from the program EVALXARTA (Xarxa de Referència en Tecnologia dels Aliments de la Generalitat de Catalunya). In part, this study was made possible by a grant from the regional authorities of Navarra awarded to Mercedes Alemán.

\section{Conflict of interest}

The authors have declared no conflict of interest. 


\section{References}

[1] Benoist, B., McLean, E., Cogswell, M., Egli, I., Wojdyla, D: Worldwide prevalence of anaemia 19932005 : WHO global database on anaemia, WHO Press, Geneva (Switzerland) 2008.

[2] WHO: Iron Deficiency Anaemia Assessment, Prevention, and Control. WHO Press, Geneva (Switzerland) 2001.

[3] Baltussen, R. , Knai, C., Sharan, M., Iron fortification and iron supplementation are cost-effective interventions to reduce iron deficiency in four subregions of the world. J. Nutr. 2004, 134, 2678-2684.

[4] Gera, T., Sachdev, H. S., Boy, E., Effect of iron-fortified foods on hematologic and biological outcomes: Systematic review of randomized controlled trials. Am. J. Clin. Nutr. 2012, 96, 309-324.

[5] Lamounier, J. A., Capanema, F. D., da Silva Rocha, D., de Oliveira, J. E. D., Costa da Silva, M., de Almeida, C. A. N., Iron fortification strategies for the control of childhood anemia in Brazil. J. Trop. Pediatr. 2010 $56,448-451$.

[6] Walter, T., Hertrampf, E., Pizarro, F., Olivares, M., Llaguno, S., Letelier, A., Vega, V., Stekel, A., Effect of bovine-hemoglobin-fortified cookies on iron status of schoolchildren: A nationwide program in Chile. Am. J. Clin. Nutr. 1993, 57, 190-194.

[7] Trinidad, T. P., Kurilich, A. C., Mallillin, A. C., Walcyzk, T., Sagum, R. S., Singh, N. N., Harjani, Y., de Leon, M. P., Capanzana, M. V., Fletcher, J., Iron absorption from NaFeEDTA-fortified oat beverages with or without added vitamin C. Int. J. Food Sci. Nutr., 2014, 65, 124-128.

[8] Quintero-Gutiérrez, A. G., Mariaca-Gaspar, G. I., Villanueva-Sánchez, J., Polo, J., Rodríguez, C., González-Rosendo, G., Acceptability and use of heme-iron concentrate roduct added to chocolate biscuit filling as an alternative source of a highly available form of iron. CYTA - J. Food, 2012, 10, 112118.

[9] Conrad, M. E., Umbreit, J. N., Pathways of iron absorption. Blood Cells. Mol. Dis. 2002, 29, 336-355.

[10] Lynch, S., Food iron absorption and its importance for the design of food fortification strategies. Nutr. Rev., 2002, 60, S3-S6.

[11] J. Polo, C. Rodriguez: Heme iron as source of iron in food fortification. In: Handbook of food fortification and health:from concepts to public health applications. Eds. Springer Science+Business Media, V. R. Preedy, New York (USA) 2013, pp. 133-146.

[12] Roginsky, V., Zheltukhina, G. A., Nebolsin, V. E., Efficacy of metmyoglobin and hemin as a catalyst of lipid peroxidation determined by using a new testing system. J. Agric. Food Chem. 2007, 55, 67986806.

[13] Choi, S. J., Decker, E. A., McClements, D. J., Impact of iron encapsulation within the interior aqueous phase of water-in-oil-in-water emulsions on lipid oxidation. Food Chem. 2009, 116, 271-276.

[14] Zimmermann, M. B., The potential of encapsulated iron compounds in food fortification: A review. Int. J. Vitam. Nutr. Res. 2004, 74, 453-461.

[15] Bovell-Benjamin, A. C., Allen, L. H., Guinard, J.-X., Toddlers' acceptance of whole maize meal porridge fortified with Ferrous Bisglycinate. Food Qual. Prefer. 1999, 10, 123-128. 
[16] Alemán, M., Nuchi, C. D., Bou, R., Tres, A., Polo, J., Guardiola, F., Codony, R., Effectiveness of antioxidants in preventing oxidation of palm oil enriched with heme iron: A model for iron fortification in baked products. Eur. J. Lipid Sci. Technol. 2010, 112, 761-769.

[17] Alemán, M., Bou, R., Tres, A., Polo, J., Codony, R., Guardiola, F., The effect of citric acid and ascorbyl palmitate in palm oil enriched with heme iron: A model for iron fortification in bakery products. Eur. J. Lipid Sci. Technol. 2014, 116, 300-310.

[18] Asenjo, J. A., Amar, M., Cartagena, N., King, J., Hiche, E., Stekel, A., Use of a bovine heme iron concentrate in the fortification of biscuits. J. Food Sci. 1985, 50, 795-799.

[19] Mohammadi, M., Abedi, A.-S., Azizi, M. H., Ahmadian, F. S., Pouraram, H., Development of fortified biscuit using NaFeEDTA. J. Sci. Food Agric. 2011, 91, 1984-1989.

[20] Bovell-Benjamin, A. C., Allen, L. H., Frankel, E. N., Guinard, J.-X., Sensory Quality and Lipid Oxidation of Maize Porridge as Affected by Iron Amino Acid Chelates and EDTA. J. Food Sci. 1999, 64, 371-376.

[21] Hurrell, R. F.,Preventing iron deficiency through food fortification. Nutr. Rev. 1997, 55, 210-222.

[22] M. B. Zimmermann, E. J. Windhab: Encapsulation of iron and other micronutrients for food fortification. In: Encapsulation Technologies for Active Food Ingredients and Food Processing. Eds. Springer Science+Business Media, N.J. Zuidam, V.A. Nedovic, New York (USA) 2010, pp. 187-209.

[23] Oshinowo, T., Diosady, L. L., Yusufali, R., Wesley, A. S., Production of iron premix for the fortification of table salt. Int. J. Food Eng. 2012, 8, 1-24.

[24] Blanco-Rojo, R., Pérez-Granados, A. M., Toxqui, L., González-Vizcayno, C., Delgado, M. A., Vaquero, M. P., Efficacy of a microencapsulated iron pyrophosphate-fortified fruit juice: A randomised, double-blind, placebo-controlled study in Spanish iron-deficient women. Br. J. Nutr. 2011, 105, 1652-1659.

[25] Abbasi, S., Azari, S., Efficiency of novel iron microencapsulation techniques: fortification of milk. Int. J. Food Sci. Technol. 2011, 46, 1927-1933.

[26] Jayalalitha, V., Balasundaram, B., Palanidoral, B., Naresh Kumar, C. N., Fortification of encapsulated iron in probiotic yoghurt. Int. J. Agric. Res. Rev. 2012, 2, 80-84.

[27] Gupta, C., Chawla, P., Arora, S., Tomar, S. K., Singh, A. K., Iron microencapsulation with blend of gum arabic, maltodextrin and modified starch using modified solvent evaporation method - Milk fortification. Food Hydrocoll. 2015, 43, 622-628.

[28] Kwak, H. S., Yang, K. M., Ahn, J., Microencapsulated Iron for Milk Fortification. J. Agric. Food Chem. 2003, 51, 7770-7774.

[29] Kwak, H. S., Ju, Y. S., Ahn, H. J., Ahn, J., Lee, S., Microencapsulated Iron Fortification and Flavor Development in Cheddar Cheese. Asian-Australasian J. Anim. Sci. 2003, 16, 1205-1211.

[30] González-Rosendo, G., Polo, J., Rodríguez-Jerez, J. J., Puga-Díaz, R., Reyes-Navarrete, E. G., QuinteroGutiérrez, A. G., Bioavailability of a heme-iron concentrate product added to chocolate biscuit filling in adolescent girls living in a rural area of Mexico. J. Food Sci. 2010, 75, H73-H78.

[31] European Communities Commision (EEC). Regulation No. 2568/91 of 11 July 1991 on the characteristics of olive oil and olive-residue oil and on the relevant methods of analysis. Off. J. Eur. Communities. 1991, 248, 1-83. 
[33] European Comunities Commission (EEC). COMMISSION DIRECTIVE 2008/100/EC of 28 October 2008 amending Council Directive 90/496/EEC on nutrition labelling for foodstuffs as regards recommended daily allowances, energy conversion factors and definitions, 2008.

[34] Guardiola, F., Codony, R., Rafecas, M., Boatella, J., López, A., Fatty Acid Composition and Nutritional Value of Fresh Eggs, from Large- and Small-Scale Farms. J. Food Compos. Anal. 1994, 7, 171-188.

[35] Navas, J. A., Tres, A., Codony, R., Boatella, J., Bou, R., Guardiola, F., Modified ferrous oxidation-xylenol orange method to determine lipid hydroperoxides in fried snacks," Eur. J. Lipid Sci. Technol. 2004, 106, 688-696.

[36] Hornsey, H. C., The color of cooked pork. I. Estimation of the nitric oxide/heme pigments. J. Sci. Food Agric. 1956, 7, 534-540.

[37] Bou, R., Codony, R., Tres, A., Decker, E. A., Guardiola, F., Determination of hydroperoxides in foods and biological samples by the ferrous oxidation-xylenol orange method: A review of the factors that influence the method's performance. Anal. Biochem. 2008, 377, 1-15.

[38] Grau, A., Codony, R., Rafecas, M., Barroeta, A. G., Guardiola, F.,Lipid hydroperoxide determination in dark chicken meat through a ferrous oxidation-xylenol orange method. J. Agric. Food Chem. 2000, 48, 4136-4143.

[39] Tres, A., Nuchi, C. D., Bou, R., Codony, R., Guardiola, F., Assessing rabbit and chicken tissue susceptibility to oxidation through the ferrous oxidation-xylenol orange method. Eur. J. Lipid Sci. Technol. 2009, 111, 563-573.

[40] A. Tres, G. van der Veer, M. Alewijn, E. Kok, and S. M. van Ruth: Palm oil authentication: Classical methodology and state-of the-art techniques. In: Oil Palm: Cultivation, Production and Dietary Components. Nova Science Publishers, Inc.,Wageningen (Netherlands) 2011, pp. 1-44.

[41] Gordon, M. H., Kourimskb, L., Effect of antioxidants on losses of tocopherols during deep-fat frying. Food Chem. 1995, 52, 175-177.

[42] Beddows, C. G., Jagait, C., Kelly, M. J.,Effect of ascorbyl palmitate on the preservation of $\alpha$-tocopherol in sunflower oil, alone and with herbs and spices. Food Chem. 2001, 73, 255-261.

[43] Kancheva, V., Slavova-Kazakova, A., Fabbri, D., Dettori, M. A., Delogu, G., Janiak, M., Amarowicz, R., Protective effects of equimolar mixtures of monomer and dimer of dehydrozingerone with $\alpha$ tocopherol and/or ascorbyl palmitate during bulk lipid autoxidation. Food Chem. 2014, 157, 263-274.

[44] Masson, L., Robert, P., Dobarganes, M. C., Urra, C., Romero, N., Ortiz, J., Goicoechea, E., Pérez, P., Salamé, M., Torres, R., Stability of potato chips fried in vegetable oils with different degree of unsaturation. Effect of ascorbyl palmitate during storage. Grasas y Aceites. 2002, 53, 190-198.

[45] Marinova, E. M., Yanishlieva, N. V., Inhibited Oxidation of lipids III: On the activity of ascorbyl palmitate during the autoxidation of two types of lipid systems in the presence of alpha-tocopherol. Fat Sci Technol. 1992, 94, 448-452.

[46] Let, M. B., Jacobsen, C., Meyer, A., Ascorbyl palmitate, gamma-tocopherol, and EDTA affect lipid oxidation in fish oil enriched salad dressing differently. J. Agric. Food Chem. 2007, 55, 2369-2375. 
[47] D. L. Madhavi, R. S. Singhal,P. R. Kulkarni: Technological aspects of food antioxidants. In: Food Antioxidants. Eds. Marcel Decker, D. L. Madhavi, S. S. Deshpande, and D. K. Salunkhe, New York (USA) 1996, pp. 159-265.

[48] Márquez-Ruiz, G., Ruiz-Méndez, M. V., Velasco, J., Antioxidants in frying: Analysis and evaluation of efficacy. Eur. J. Lipid Sci. Technol. 2014, 116, 1441-1450.

[49] Alvarez, C., Rendueles, M., Díaz, M., Production of porcine hemoglobin peptides at moderate temperature and medium pressure under a nitrogen stream. Functional and antioxidant properties. $J$. Agric. Food Chem. 2012, 60, 5636-43.

[50] Chang, C.-Y., Wu, K.-C., Chiang, S.-H., Antioxidant properties and protein compositions of porcine haemoglobin hydrolysates. Food Chem. 2007, 100, 1537-1543.

[51] Sun, Q. , Luo, Y., Shen, H., Hu, X., Effects of $\mathrm{pH}$, temperature and enzyme to substrate ratio on the antioxidant activity of porcine hemoglobin hydrolylate prepared with pepsin. J. Food Biochem. 2011, $35,44-61$.

[52] Tompkins, C., Perkins, E. G., Evaluation of frying oils with the p-anisidine value. J. Am. Oil Chem. Soc. 1999, 76, 945-947.

[53] Zajdenwerg, C., Branco, G. F., Alamed, J., Decker, E. A., Castro, I. A., Correlation between sensory and chemical markers in the evaluation of Brazil nut oxidative shelf-life. Eur. Food Res. Technol. 2011, 233, 109-116.

[54] Frankel, E. N., Neff, W. E., Selke, E., Analysis of autoxidized fats by gas chromatography-mass spectrometry: VII. Volatile thermal decomposition products of pure hydroperoxides from autoxidized and photosensitized oxidized methyl oleate, linoleate and linolenate. Lipids. 1981, 16, 279-285.

[55] Choe E., Min, D. B., Mechanisms and Factors for Edible Oil Oxidation. Compr. Rev. Food Sci. Food Saf. 2006, 5, 169-186.

[56] Zamora, R., Hidalgo, F. J., The Maillard reaction and lipid oxidation. Lipid Technol. 2011, 23, 59-62. 


\section{Supplementary information}

Production of heme iron ingredients: The control heme iron (AproFER $1000^{\mathrm{TM}}$ ) is a dark powder obtained from the blood of healthy pigs. After separating the blood cell fraction by centrifugation, a pressure pump was used to release the haemoglobin contained in the red blood cells. Then, the haemoglobin was enzymatically hydrolysed using a proteolytic enzyme (Alcalase ${ }^{\circledR}$, Novo-Nordisk, Denmark) under controlled pH and temperature conditions. The heme group was then concentrated by ultrafiltration and spray-dried.

The co-spray-dried heme iron ingredients were prepared from the heme iron concentrate obtained by ultrafiltration. After analysing its solid content, the concentrate was mixed with the appropriate amount of cospray-drying agent. In the case of the co-spray-dried ingredients in a ratio of 1:1, the same amount of co-spraydrying agent as of the solid content of the concentrate was added. In the case of the co-spray-dried ingredients in a ratio of 2:1, half the amount of co-spray-drying agent was added to the concentrate. In both cases, the cospray-drying agents were dispersed at $40^{\circ} \mathrm{C}$ with continuous stirring; thereafter the $\mathrm{pH}$ was set at 8.00 , as is normal during the production of the AproFER $1000^{\mathrm{TM}}$. All the dispersion mixtures, with or without co-spraydrying agents, were dried on a pilot plant spray-dryer (Anhydro Compact Spray Dryer, Anhydro A/S, Copenhagen, Denmark).

Mineralization of samples and heme iron ingredients: For heme iron dispersions in sunflower oil and palm oil, 1 g samples were weighed in a glass beaker and $2 \mathrm{~mL}$ of $\mathrm{H}_{2} \mathrm{SO}_{4}$ was added. Then the samples were placed in a sand bath at $250^{\circ} \mathrm{C}$. When the samples were smoking, an additional $2 \mathrm{~mL}$ of $\mathrm{H}_{2} \mathrm{SO}_{4}$ was added. The samples were then again placed in the sand bath at $250^{\circ} \mathrm{C}$ and allowed to dry. Afterwards, the samples were calcined in a muffle furnace at $450^{\circ} \mathrm{C}$ for $10 \mathrm{~h}$ (rate of heating $1^{\circ} \mathrm{C} / \mathrm{min}$ ). The following day, $1 \mathrm{~mL}$ of $\mathrm{H}_{2} \mathrm{SO}_{4}$ was added, allowed to dry and subsequently calcined again for $2 \mathrm{~h}$ in the muffle furnace at $450^{\circ} \mathrm{C}$. Finally, the samples were redissolved in $2 \mathrm{~mL}$ of $\mathrm{HCl}$ and diluted to a final volume of $100 \mathrm{~mL}$ with $1 \% \mathrm{HNO}_{3}$.

The different heme iron ingredients were mineralized as follows: $250 \mathrm{mg}$ of the ingredient was weighed in a glass beaker. Following this, $2 \mathrm{~mL}$ of $\mathrm{H}_{2} \mathrm{SO}_{4}$ was added to the sample. The sample was then placed in a sand bath at $250^{\circ} \mathrm{C}$ until dry. The ingredient was then calcined in a muffle furnace at $450^{\circ} \mathrm{C}$ for $10 \mathrm{~h}$ (rate of heating $1^{\circ} \mathrm{C} / \mathrm{min}$ ). After the heat treatment, $1 \mathrm{~mL}$ of $\mathrm{H}_{2} \mathrm{SO}_{4}$ was added and allowed to dry in the sand bath at $300^{\circ} \mathrm{C}$. Finally, a second heat treatment was applied in the muffle furnace at $450^{\circ} \mathrm{C}$ for a period of $3-6 \mathrm{~h}$. The samples were then re-dissolved in $2 \mathrm{~mL}$ of $\mathrm{HCl}$ and diluted to a final volume of $100 \mathrm{~mL}$ with $1 \% \mathrm{HNO}_{3}$. 
Table 1. Heme iron ingredients and antioxidant concentrations added to the palm oil to prepare the different treatments.

\begin{tabular}{|c|c|c|}
\hline Treatments & Heme iron ingredients $^{a}$ & AP $[\mathrm{mg} / \mathrm{kg}]$ \\
\hline Control & AproFER $1000^{\mathrm{TM}}$ & 0 \\
\hline CAS 2:1 & $2: 1, w / w$, heme iron concentrate:CAS ${ }^{b}$ & 0 \\
\hline CAS 1:1 & $1: 1, w / w$, heme iron concentrate:CAS & 0 \\
\hline CAS & AproFER $1000^{\mathrm{TM}}+\mathrm{CAS}^{\mathrm{C}}$ & 0 \\
\hline AP & AproFER $1000^{\mathrm{TM}}$ & 400 \\
\hline CAS $2: 1+$ AP & $2: 1, w / w$, heme iron concentrate:CAS & 400 \\
\hline CAS $1: 1+A P$ & $1: 1, w / w$, heme iron concentrate:CAS ${ }^{b}$ & 400 \\
\hline
\end{tabular}

Abbreviations: CAS, calcium caseinate; AP, ascorbyl palmitate.

${ }^{a}$ Manufacturing of heme iron ingredients is described in supplementary information.

${ }^{\mathrm{b}}$ The heme iron concentrate was co-spray dried with CAS.

${ }^{\mathrm{C}}$ Mixture of AproFER $1000^{\mathrm{TM}}$ and CAS $(1: 1, \mathrm{w} / \mathrm{w})$ without being co-spray-dried.

The addition of the heme iron ingredients was carried in such a way that all samples had the same iron concentration (1.20 mg Fe/g sample). 
Table 2. Fatty acid composition (expressed as area normalization in percentage) of the palm oil used to prepare the different fortified (treatment) samples.

\begin{tabular}{|c|c|}
\hline Fatty Acid $^{\mathrm{a}}$ & Mean [\%] $\pm S D(n=5)$ \\
\hline $10: 0$ & $0.03 \pm<0.01$ \\
\hline $12: 0$ & $0.42 \pm<0.01$ \\
\hline 14:0 & $1.14 \pm 0.01$ \\
\hline $15: 0$ & $0.05 \pm<0.01$ \\
\hline $16: 0$ & $42.84 \pm 0.1$ \\
\hline $16: 1 n-9$ & $0.03 \pm<0.01$ \\
\hline $16: 1 n-7$ & $0.16 \pm<0.01$ \\
\hline $17: 0$ & $0.10 \pm<0.01$ \\
\hline $17: 1$ & $0.02 \pm<0.01$ \\
\hline 18:0 & $4.76 \pm 0.02$ \\
\hline $18: 1 \mathrm{t}$ & $0.11 \pm 0.01$ \\
\hline $18: 1 n-9$ & $38.71 \pm 0.09$ \\
\hline $18: 1 n-7$ & $0.75 \pm 0.06$ \\
\hline $18: 2 n-6$ & $9.99 \pm 0.02$ \\
\hline $18: 3 n-3$ & $0.15 \pm<0.01$ \\
\hline $20: 0$ & $0.41 \pm<0.01$ \\
\hline $20: 1 n-9$ & $0.15 \pm<0.01$ \\
\hline $20: 2 n-6$ & $0.03 \pm<0.01$ \\
\hline $20: 3 n-6$ & $0.08 \pm<0.01$ \\
\hline $24: 0$ & $0.08 \pm<0.01$ \\
\hline SFA & $49.83 \pm 0.08$ \\
\hline MUFA & $39.93 \pm 0.06$ \\
\hline PUFA & $10.24 \pm 0.01$ \\
\hline PUFA n-6 & $10.09 \pm 0.01$ \\
\hline PUFA n-3 & $0.15 \pm<0.01$ \\
\hline Trans FA & $0.11 \pm 0.01$ \\
\hline
\end{tabular}

${ }^{a}$ SFA = saturated fatty acid, MUFA = monounsaturated fatty acid, PUFA = polyunsaturated fatty acid, Trans FA $=$ trans fatty acid 
Table 3. Tocopherol and tocotrienol composition of the native palm oil and that of the palm oils obtained by filtration from the fortified (treatment) samples heated at 220 ${ }^{\circ} \mathrm{C}$ for $10 \mathrm{~min}$ (filtration was carried after heating to remove heme iron particles from fortified samples).

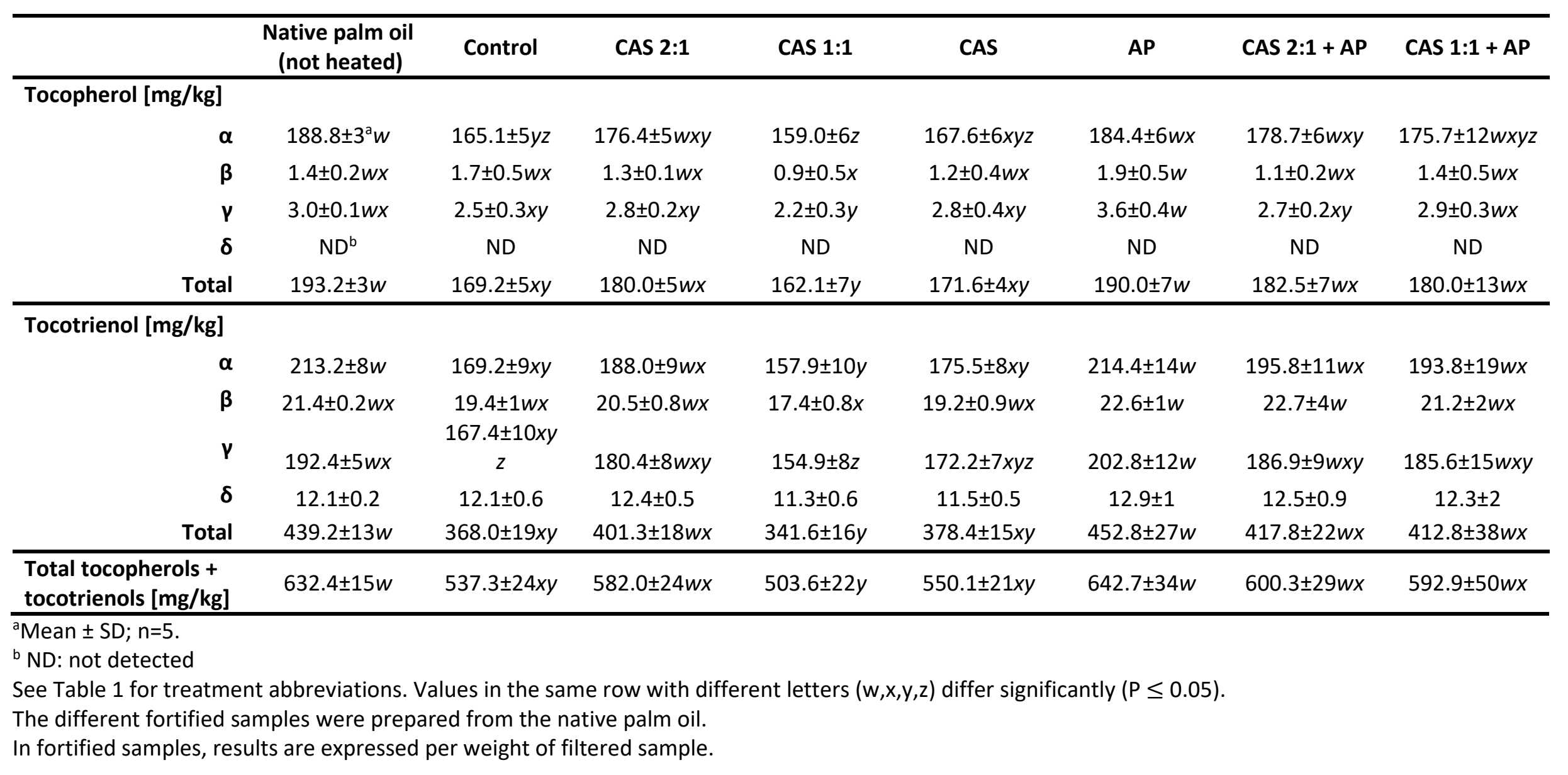


Table 4. Total iron and heme iron content of ingredients and samples used in the preliminary and main studies.

\begin{tabular}{|c|c|c|c|c|}
\hline & \multicolumn{2}{|c|}{ Heme iron ingredients } & \multicolumn{2}{|c|}{$\begin{array}{c}\text { Fortified oil samples } \\
\text { (after heating, prior to storage) }\end{array}$} \\
\hline Treatments & $\begin{array}{l}\text { \% IRON } \\
\text { in the } \\
\text { ingredient } \\
\end{array}$ & $\begin{array}{l}\text { \% HEME IRON } \\
\text { relative to total iron }\end{array}$ & 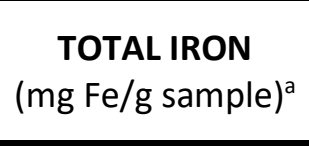 & $\begin{array}{c}\text { \% HEME IRON } \\
\text { relative to } \\
\text { total iron } \\
\end{array}$ \\
\hline \multicolumn{5}{|l|}{ Sunflower oil study } \\
\hline Control $^{\mathrm{b}}$ & $1.34 \pm 0.05$ & $93 \pm 0.2$ & $1.20 \pm 0.02$ & $107 \pm 0.1$ \\
\hline CAS $2: 1^{b}$ & $0.98 \pm 0.09$ & $92 \pm 0.1$ & $1.35 \pm 0.01$ & $99 \pm<0.1$ \\
\hline CAS $1: 1^{b}$ & $0.80 \pm 0.04$ & $92 \pm 0.1$ & $1.31 \pm 0.02$ & $107 \pm 0.1$ \\
\hline ST-MD 2:1 ${ }^{b}$ & $0.96 \pm 0.06$ & $90 \pm 0.1$ & $1.25 \pm 0.04$ & $106 \pm<0.1$ \\
\hline ST-MD 1:1 ${ }^{\mathrm{b}}$ & $0.74 \pm 0.05$ & $94 \pm 0.1$ & $1.24 \pm 0.04$ & $99 \pm<0.1$ \\
\hline Average & - & $92 \pm 1$ & $1.27 \pm 0.06$ & $104 \pm 4$ \\
\hline \multicolumn{5}{|l|}{ Palm oil study } \\
\hline AproFER $1000^{\mathrm{TM}} \mathrm{c}$ & $1.07 \pm 0.01$ & 84 & $1.30 \pm 0.25$ & $73 \pm 0.2$ \\
\hline CAS 2:1 $1^{d}$ & $0.75 \pm 0.00$ & 80 & $1.12 \pm 0.00$ & $71 \pm<0.1$ \\
\hline CAS $1: 1^{e}$ & $0.58 \pm 0.01$ & 86 & $1.13 \pm 0.04$ & $74 \pm 0.1$ \\
\hline Average & - & $83 \pm 3$ & $1.20 \pm 0.16$ & $73 \pm 2$ \\
\hline
\end{tabular}

See Table 1 and Figure 1 for treatment abbreviations.

Results are expressed as Mean \pm SD

${ }^{a}$ Total iron in fortified oil samples is expressed per weight of whole sample (non-filtered samples, containing heme iron particles).

${ }^{b}$ In the sunflower oil study, for the heme iron ingredients, $n=5$; and for the fortified oil samples, $n=3$.

${ }^{\mathrm{C}}$ Means calculated with all treatments with AproFER $1000^{\mathrm{TM}}$ (control, CAS and AP), $\mathrm{n}=15$.

${ }^{d}$ Means calculated with all treatments with CAS 2:1 heme iron ingredient (CAS 2:1 and CAS 2:1 + AP), $n=10$.

${ }^{e}$ Means calculated with all treatments with CAS 1:1 heme iron ingredient (CAS 1:1 and CAS 1:1 + AP), $n=10$. 
Table 5. Susceptibility to lipid oxidation of fortified palm oil samples prior to storage measured by means of the FOX-induced method $(n=5)$. The parameters determined from the curve of formation of lipid hydroperoxides were: initial lipid hydroperoxide value (Initial LHP), maximum lipid hydroperoxide value (MAXLHP), time to reach the maximum lipid hydroperoxide value (TMAX), final lipid hydroperoxide value (Final LHP) and the area under the curve (AUC).

\begin{tabular}{|c|c|c|c|c|c|}
\hline Treatment & $\begin{array}{c}\text { Initial LHP } \\
{[\mathrm{mmol} \text { CHP eq/kg] }}\end{array}$ & $\begin{array}{c}\text { MAXLHP } \\
{[\mathrm{mmol} \text { CHP eq } / \mathrm{kg}]}\end{array}$ & $\begin{array}{c}\text { TMAX } \\
\text { [h] }\end{array}$ & $\begin{array}{c}\text { Final LHP } \\
{[\mathrm{mmol} \text { CHP eq } / \mathrm{kg}]}\end{array}$ & $\begin{array}{c}\text { AUC } \\
{[(\mathrm{mmol} C H P \text { eq }} \\
/ \mathrm{kg}) \times \mathrm{h}] \\
\end{array}$ \\
\hline Control & $0.08 \pm 0.02^{\mathrm{a} x}$ & $0.13 \pm 0.02 x$ & 24 & $0.04 \pm<0.01 x y$ & $14.26 \pm 1.18 x$ \\
\hline CAS 2:1 & $0.05 \pm<0.01 x$ & $0.10 \pm<0.01 x$ & 24 & $0.03 \pm 0.01 x$ & $11.65 \pm 1.15 x$ \\
\hline CAS $1: 1$ & $0.21 \pm<0.01 y$ & $0.23 \pm<0.01 y$ & 2.5 & $0.06 \pm 0.01 y z$ & $19.00 \pm 1.20 y$ \\
\hline CAS & $0.26 \pm 0.04 z$ & $0.27 \pm 0.04 y$ & 2.5 & $0.07 \pm 0.01 z$ & $21.10 \pm 1.85 y$ \\
\hline AP & $0.07 \pm 0.02 x$ & $0.13 \pm 0.01 x$ & 24 & $0.05 \pm 0.01 x y z$ & $14.42 \pm 1.09 x$ \\
\hline CAS 2:1 + AP & $0.03 \pm<0.01 x$ & $0.11 \pm 0.01 x$ & 43.5 & $0.05 \pm 0.01 x y z$ & $12.54 \pm 0.77 x$ \\
\hline CAS $1: 1+A P$ & $0.04 \pm<0.01 x$ & $0.12 \pm 0.01 x$ & 48 & $0.05 \pm 0.01 x y z$ & $13.62 \pm 0.89 x$ \\
\hline
\end{tabular}

${ }^{a}$ Mean $\pm S D ; n=5$.

See Table 1 for treatment abbreviations.

Values in the same column with different letters $(x, y, z)$ differ significantly $(P \leq 0.05)$.

Results are expressed per weight of filtered sample. 
Table 6. Effect of treatment and storage time (at room temperature in the dark, 360 days) on oxidation parameters (PV; LHP content; $p$-AnV and hexanal content) of fortified palm oil samples.

\begin{tabular}{|c|c|c|c|c|}
\hline & $\begin{array}{c}\mathrm{PV} \\
{\left[\mathrm{mEq} \mathrm{O}_{2} / \mathrm{kg}\right]}\end{array}$ & $\begin{array}{c}\text { LHP content } \\
{[\mathrm{mmol} \mathrm{CHP} / \mathrm{kg}]}\end{array}$ & $p$-AnV & $\begin{array}{c}\text { Hexanal content } \\
{[\mathrm{mg} / \mathrm{kg}]}\end{array}$ \\
\hline \multicolumn{5}{|l|}{ Treatment $^{a}$} \\
\hline Control & $11.9 u$ & $11.5 v$ & $4.0 x$ & $137.5 w x$ \\
\hline CAS 2:1 & $16.1 v$ & $14.9 w$ & $3.5 w$ & $107.9 v$ \\
\hline CAS 1:1 & $20.9 w$ & $16.9 w$ & $4.9 z$ & $72.8 u$ \\
\hline CAS & $10.1 u$ & $8.5 u$ & $4.6 y$ & $125.9 v w x$ \\
\hline AP & $8.7 u$ & $9.5 u v$ & $3.7 w x$ & $145.3 x$ \\
\hline CAS $2: 1+A P$ & $20.1 w$ & $17.1 w$ & $2.5 v$ & $114.8 v w$ \\
\hline CAS $1: 1+A P$ & $10.2 u$ & $11.5 v$ & $2.2 u$ & $60.8 u$ \\
\hline SEM $^{b}$ & 0.98 & 0.72 & 0.08 & 7.2 \\
\hline \multicolumn{5}{|l|}{ Storage time $\mathrm{e}^{\mathrm{a}}$} \\
\hline 0 days & $0.1 u$ & $0.1 u$ & $3.0 u$ & $\mathrm{ND}^{c} u$ \\
\hline 90 days & $10.2 v$ & $9.5 \mathrm{v}$ & $3.3 v$ & $21.2 v$ \\
\hline 180 days & $17.1 w$ & $16.1 w$ & $3.7 w$ & $220.5 w$ \\
\hline 360 days & $28.6 x$ & $25.6 x$ & $4.4 x$ & $195.5 x$ \\
\hline SEM $^{b}$ & 0.74 & 0.54 & 0.06 & 5.4 \\
\hline \multicolumn{5}{|l|}{ Time $0^{d}$} \\
\hline Control & $0.38 w$ & $0.08 v$ & $3.4 v$ & ND \\
\hline CAS 2:1 & $0.05 u$ & $0.05 u v$ & $3.4 v$ & ND \\
\hline CAS 1:1 & $0.09 u$ & $0.21 w$ & $5.3 w$ & ND \\
\hline CAS & $0.24 v$ & $0.26 w$ & $3.2 v$ & ND \\
\hline AP & $0.09 u$ & $0.07 u v$ & $2.0 u$ & ND \\
\hline CAS 2:1 + AP & $0.04 u$ & $0.03 u$ & $1.9 u$ & ND \\
\hline CAS $1: 1+A P$ & $0.05 u$ & $0.04 u v$ & $1.9 u$ & ND \\
\hline SEM $^{\mathrm{e}}$ & 0.02 & 0.01 & 0.09 & 0 \\
\hline \multicolumn{5}{|l|}{ Time $360^{d}$} \\
\hline Control & $23.1 u v$ & $22.6 u v w$ & $5.2 x y$ & $233.9 v$ \\
\hline CAS 2:1 & $32.9 v w$ & $28.3 v w x$ & $4.2 w$ & $189.5 u v$ \\
\hline CAS $1: 1$ & $41.6 w$ & $30.8 w x$ & $4.9 x$ & $152.2 u v$ \\
\hline CAS & $19.9 u$ & $12.8 u$ & $5.5 y$ & $207.1 u v$ \\
\hline AP & $15.1 u$ & $19.1 u v$ & $4.9 x$ & $233.1 v$ \\
\hline CAS $2: 1+A P$ & $41.2 w$ & $33.6 x$ & $3.7 v$ & $216.9 u v$ \\
\hline CAS $1: 1+A P$ & $26.6 u v$ & $32.3 w x$ & $2.7 u$ & $135.5 u$ \\
\hline SEM $^{\mathrm{e}}$ & 3.1 & 2.6 & 0.12 & 22 \\
\hline
\end{tabular}

${ }^{a}$ Values correspond to least-squares means obtained from multifactor ANOVA ( $\left.n=140\right)$.

${ }^{b}$ Standard error of the least-squares means.

${ }^{\mathrm{C} N D}$ : not detected

${ }^{d}$ Values correspond to means obtained from ANOVA $(n=35)$

e Standard error of the means

See Table 1 for treatment abbreviations. PV: peroxide value; LHP content: lipid hydroperoxide content measured through the non-induced FOX method; $p$-AnV: $p$-anisidine value.

PV, LHP content and $p$-AnV were determined in filtered samples. Hexanal content was determined in the whole samples (non-filtered samples, containing heme iron particles). Results are expressed per weight of filtered or whole sample, accordingly. 
Values corresponding to a certain factor with different letters $(u, v, w, x, y, z)$ differ significantly $(P \leq 0.05)$. 
Table 7. Palm oil characteristics and oxidation status of control samples from different studies after heating at $220^{\circ} \mathrm{C}$ for $10 \mathrm{~min}$ (prior to storage) and after 180 or 200 days of storage at room temperature in the dark.

\begin{tabular}{rccc}
\cline { 2 - 4 } & $\begin{array}{c}\text { Study 1 } \\
\text { (Alemán et al., 2010) }\end{array}$ & $\begin{array}{c}\text { Study 2 (Alemán } \\
\text { et al., 2014) }\end{array}$ & Present study \\
\hline $\begin{array}{r}\text { Characteristics of palm oils used to prepare } \\
\text { samples fortified with heme iron }\end{array}$ & & & \\
MUFA \% & $38.94 \pm<0.01^{\mathrm{a}}$ & $39.87 \pm 0.20$ & $39.93 \pm 0.06$ \\
PUFA \% & $10.83 \pm<0.01$ & $9.62 \pm 0.05$ & $10.24 \pm 0.01$ \\
Linoleic acid \% & $10.52 \pm<0.01$ & $9.37 \pm 0.05$ & $9.99 \pm 0.02$ \\
Linolenic acid \% & $0.19 \pm<0.01$ & $0.14 \pm<0.01$ & $0.15 \pm<0.01$ \\
Total tocopherols [mg/kg] & $133.8 \pm 6$ & $146.4 \pm 6$ & $193.2 \pm 3$ \\
Total tocotrienols [mg/kg] & $397.1 \pm 14$ & $322.7 \pm 12$ & $439.2 \pm 13$ \\
Total tocopherols + tocotrienols [mg/kg] & $530.9 \pm 14$ & $469.1 \pm 17$ & $632.4 \pm 14$
\end{tabular}

\section{Susceptibility to oxidation of control samples fortified}

with heme iron (prior to storage)

Loss of tocopherols + tocotrienols during

heating [\%]

$13.2 \pm 2$

$20.2 \pm 5$

$12.7 \pm 2$

AUC $[(\mathrm{mmol} \mathrm{CHP} / \mathrm{kg}) \mathrm{xh}]$

$10.37 \pm<0.01$

$31.73 \pm<0.01$

$14.27 \pm 0.01$

Oxidation parameters of control samples fortified

with heme iron (over storage time)

\begin{tabular}{rrrrr}
$\mathrm{PV}\left[\mathrm{mEq} \mathrm{O}_{2} / \mathbf{k g}\right]$ & $\mathbf{0}$ days & $0.7 \pm 0.01$ & $3.3 \pm 0.21$ & $0.4 \pm<0.01$ \\
& $\mathbf{1 8 0}$ or $\mathbf{2 0 0}$ days & $24.6 \pm 0.37$ & $25.3 \pm 0.69$ & $13.8 \pm 0.24$ \\
\hline LHP [mmol CHP/kg] & $\mathbf{0}$ days & $0.1 \pm<0.01$ & $1.8 \pm<0.01$ & $0.08 \pm 0.02$ \\
& $\mathbf{1 8 0}$ or $\mathbf{2 0 0}$ days & $18.5 \pm 0.25$ & $20.1 \pm 0.51$ & $14.7 \pm 0.94$ \\
\hline $\boldsymbol{p}$ p-AnV & $\mathbf{0}$ days & $3.4 \pm 0.01$ & $2.9 \pm 0.06$ & $3.4 \pm 0.05$ \\
& $\mathbf{1 8 0}$ or $\mathbf{2 0 0}$ days & $4.3 \pm 0.01$ & $6.3 \pm 0.04$ & $4.0 \pm 0.61$
\end{tabular}

\begin{tabular}{|c|c|c|c|}
\hline \multicolumn{4}{|l|}{$\begin{array}{l}\text { Average iron content of fortified samples } \\
\text { (prior to storage) }\end{array}$} \\
\hline Total iron content [mg Fe/g sample] & 1.61 & $0.95 \pm 0.51$ & $1.20 \pm 0.16$ \\
\hline$\%$ Free iron & 4 & 2 & 27 \\
\hline
\end{tabular}

\footnotetext{
${ }^{a}$ Mean \pm SD

MUFA, monounsaturated fatty acid; PUFA, polyunsaturated fatty acid; AUC, area under the curve of formation of lipid hydroperoxides (induced FOX method, susceptibility to oxidation); PV, peroxide value; LHP content, lipid hydroperoxide content measured through the non-induced FOX method; $p$-AnV, $p$ anisidine value.

Control samples of the different studies were fortified with different batches of the control heme iron ingredient (AproFER 1000 ${ }^{\mathrm{TM}}$ ).

In the present study and in study 2 , the oxidation parameters were assessed in filtered samples. In study 1 , the PV and $p$-AnV were determined after removal of heme iron particles, while AUC and LHP content were determined in the whole samples, without removing the heme iron particles Therefore, only AUC and LHP contents from study 1 are expressed per weight of the whole sample; the rest of oxidation results in this table are expressed per weight of the sample, excluding heme iron particles.

The total iron content results are expressed per weight of whole sample (non-filtered samples, containing heme iron particles). In these models, the percentage of free iron is estimated subtracting the $\%$ of heme iron from 100.
} 
Samples in study 1 were stored for 200 days and compared with samples stored for 180 days in the other studies. 
Figure 1: Evolution of peroxide value (A) and $p$-anisidine value (B) during storage at $60^{\circ} \mathrm{C}$ of sunflower oil fortified with different heme iron ingredients $(n=2)$.
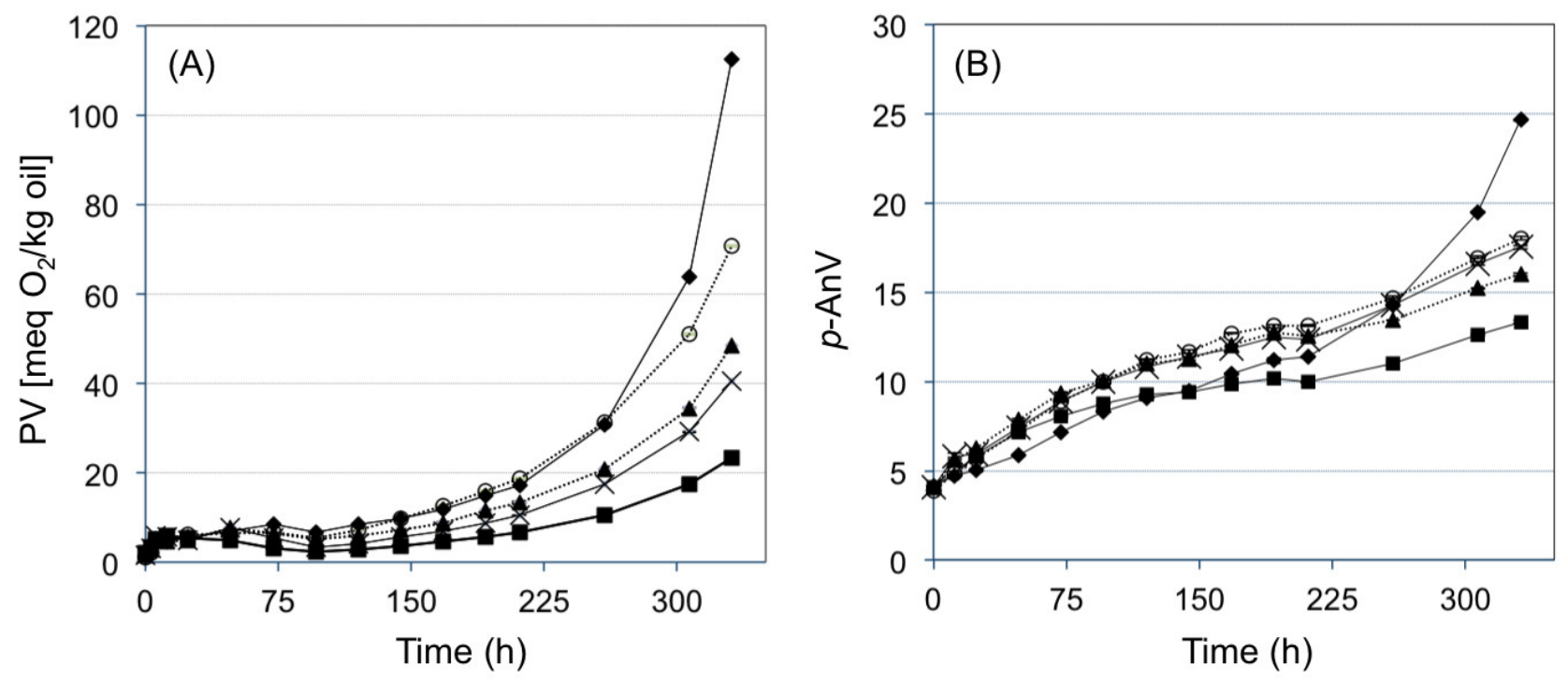

$\rightarrow$ Control $\rightarrow$ CAS 2:1 $\rightarrow$ CAS 1:1 ……ST-MD 2:1 $\cdots \cdots$ - $\cdots$ ST-MD 1:1

Where control is the treatment with the control heme iron ingredient, AproFER $1000^{\text {TM}}$; CAS 2:1 is the treatment with the heme iron ingredient co-spray-dried with calcium caseinate at 2:1 ratio (heme iron concentrate : CAS); CAS 1:1 is the treatment with the heme iron ingredient co-spray-dried with calcium caseinate at 1:1 ratio (heme iron concentrate : CAS); ST-MD 2:1 is the treatment with the heme iron ingredient co-spray-dried with a mixture of modified starch and maltodextrin $(1: 1, \mathrm{w} / \mathrm{w})$ at 2:1 ratio (heme iron concentrate : ST-MD); ST-MD 1:1 is the treatment with the heme iron ingredient co-spray-dried with a mixture of modified starch and maltodextrin $(1: 1, \mathrm{w} / \mathrm{w})$ at 1:1 ratio (heme iron concentrate : ST-MD). The error bars (standard deviations of the means, $n=2$ ) are very small and lay within the data points. 
Figure S1: Correlation between the oxidation parameters: peroxide value (PV) vs. lipid hydroperoxide content (LHP content) (A) and p-Anisidine Value ( $p$-AnV) vs. hexanal content (B).
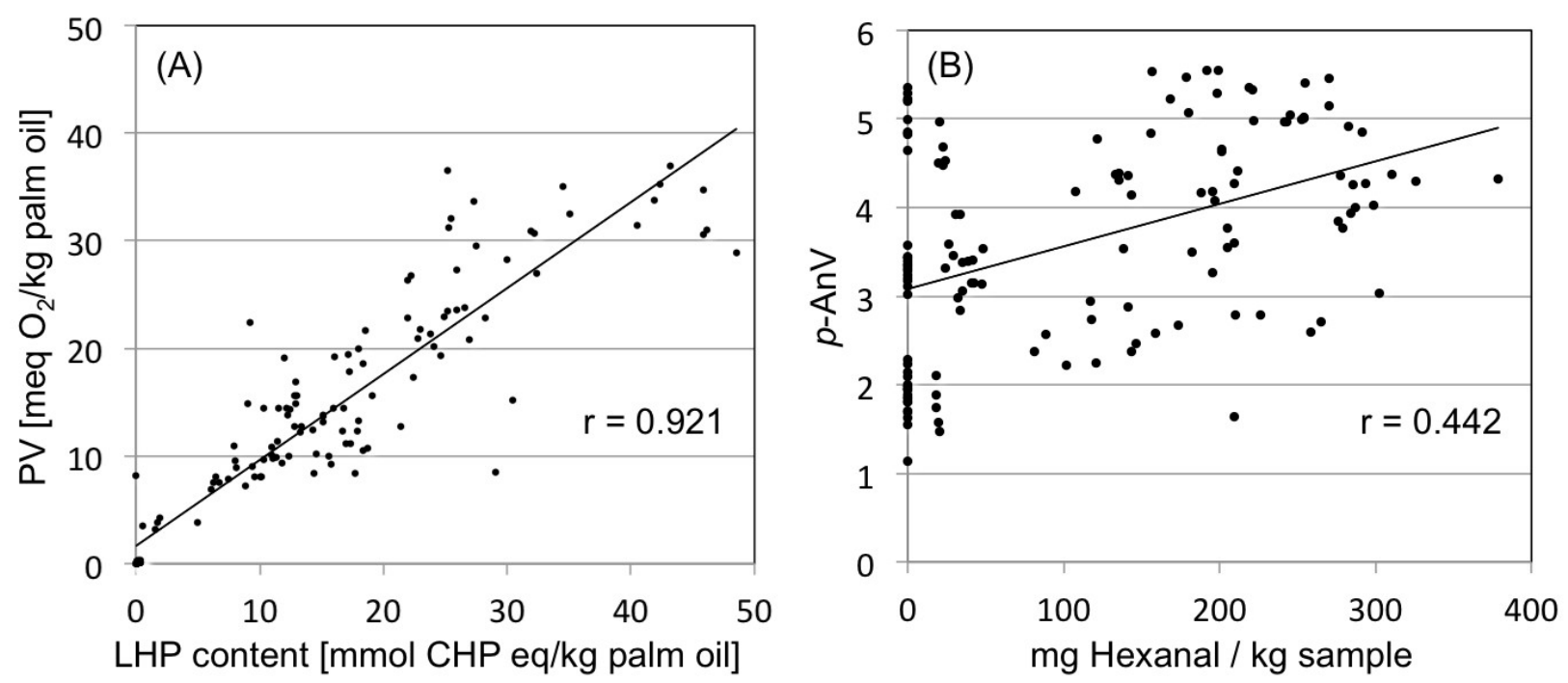